\title{
Anti-CCP2 Antibodies: An Overview and Perspective of the Diagnostic Abilities of this Serological Marker for Early Rheumatoid Arthritis
}

\author{
Walther J. van Venrooij • Albert J. W. Zendman
}

Published online: 18 September 2007

(C) Humana Press Inc. 2007

\begin{abstract}
The literature of the last 4 years confirms that the anti-CCP2 test is a very useful marker for the early and specific diagnosis of rheumatoid arthritis (RA). The antiCCP2 test is very specific for RA (95-99\%) and has sensitivity comparable to that of the rheumatoid factor (70$75 \%$ ). The antibodies can be detected very early in the disease and can be used as an indicator for the progression and prognosis of RA. In this review, these interesting properties and some future possibilities of this diagnostic test are discussed.
\end{abstract}

Keywords Autoantibodies · Rheumatoid factor Anti-cyclic citrullinated peptide $\cdot$ CCP2 test

The presence of autoantibodies in the serum of patients is a very typical phenomenon for autoimmune diseases. Most of these autoantibodies, however, can also be detected in patients with other conditions and are therefore not specific. A typical example is the rheumatoid factor (RF), which is present in most inflammatory conditions. However, in some cases, autoantibodies can give the clinician a more precise indication of the type of underlying disease because they occur specifically in a certain disease. For example, anti-Sm antibodies are linked almost exclusively to systemic lupus erythematosus (SLE); whereas anti-DNA topoisomerase-I antibodies are typically present in scleroderma patients. Among the most disease-specific autoantibodies described are the so-called ACPA (anti-citrullinated protein/peptide

W. J. van Venrooij $(\bowtie) \cdot$ A. J. W. Zendman

Department of Biomolecular Chemistry,

Radboud University Nijmegen,

Nijmegen, The Netherlands

e-mail: w.vanvenrooij@ncmls.ru.nl antibodies). These antibodies occur specifically in RA and can be measured most conveniently via the anti-CCP (anticyclic citrullinated peptide) antibody test.

Thefirstgeneration CCP test(CCP1) usedinearly diagnostic studies (2000-2001) contained a single cyclic citrullinated peptide derived from filaggrin as the substrate [1]. It could detect ACPA in $68 \%$ of patients with established RA with a very high specificity $(98 \%)$. Because filaggrin is not expressed in the synovium, it is most likely not the natural citrullinated antigen for ACPA. Other peptides, not related to filaggrin, could therefore potentially provide better epitopes for detection of ACPA. Via screening of a number of peptide libraries, novel citrullinated peptides were obtained and incorporated into a second generation CCP test (CCP2). This test is commercially available, and as all companies use the same type of CCP2 peptides, standardization is achieved quite easily. The diagnostic properties of this test will be discussed below.

\section{The CCP2 Test is Sensitive and Highly Specific for RA}

Since its appearance on the market in the second half of 2002, the diagnostic properties of the CCP2 test have been studied by many laboratories. This resulted in more than 120 publications dealing with this subject. The accumulated data, including only papers that appeared in PubMed till December 2006, are given in Table 1. It is clear that the accumulated data confirm the earliest reports on specificity and sensitivity of the CCP2 test. The anti-CCP2 test demonstrates an RF-like sensitivity with a very high specificity for RA (see also recent reviews: [2, 3]). It is also commonly recognized that anti-CCP2 antibody may be present in up to $40 \%$ of RF-negative RA sera [4, 5]. 
Table 1 Cumulative anti-CCP2 diagnostic data published between 2002 and 2006

In total, 122 independent studies were included. The selection for early RA has been adopted from the original reports.

\begin{tabular}{lrrll}
\hline Patient group & Number & CCP2+ & Sensitivity (\%) & Specificity (\%) \\
\hline RA total & 14,183 & 10,135 & 71.5 & \\
Early & 3,876 & 2,365 & 61.0 & \\
Established & 10,307 & 7,770 & 75.4 & 95.6 \\
Controls & 15,156 & 683 & 4.5 & 94.4 \\
Non-RA & 11,502 & 647 & 5.6 & 99.0 \\
Healthy & 3,654 & 36 & 1.0 & \\
\hline
\end{tabular}

The anti-CCP2 test enables clinicians to distinguish RA patients from other arthritic diseases, especially in cases where the RF test is not discriminative. This is, for example, the case with chronic hepatitis $\mathrm{C}$ virus (HCV) infection, a disease that can easily be misdiagnosed as it often reveals RA-like arthropathies and, in many cases, is accompanied by a positive RF. Several examples of such studies are given in recent reviews on this subject [6].

Recently, there is also an interest to compare the diagnostic potential of anti-CCP2 with novel tests based on the use of a citrullinated antigen (for example, MCV= anti-mutated citrullinated vimentin [7], $\mathrm{CPA}=$ citrullinated protein antibodies, $\mathrm{VCP}=$ anti-viral citrullinated protein [8], antihuman fibrinogen alpha [9, 10], and CCP3 [11]). For a reliable comparison of these tests, it is essential that their performance is assessed under the same conditions, e.g., the sensitivities of the tests should be determined at the same level of specificity. Good examples of such stratified studies have been carried out recently by van der Cruijssen et al. [10] and Dejaco et al. [7]. For example, Dejaco et al. [7] showed, in a large cohort of patients $(>600)$, that at a specificity of $98.7 \%$, being the specificity of the anti-CCP2 test, the sensitivity of the anti-MCV test is $53.7 \%$ as opposed to $70.1 \%$ for the anti-CCP test. Coenen et al. [11] compared several commercial tests, including a very recent CCP3 test from Inova. At the cut-offs recommended by the various manufacturers, the positive predictive value of the three commercial CCP2 tests is about $90 \%$ with a specificity of around $96 \%$. The specificity of the other tests $(\mathrm{CCP} 3=88 \%, \mathrm{MCV}=90 \%, \mathrm{CPA}=94 \%)$ is lower as are their positive predictive values [11]. These numbers may improve a little bit when the cut-off values are adjusted to more realistic data; nevertheless, the data allow the statement that, in absolute percentages, none of the tests performs better than the anti-CCP2 test. They also seem to indicate that some tests detect RA patient groups that are negative in the antiCCP test, illustrating again that the autoantibody repertoire of RA patients is very heterogeneous.

Another risk for the specificity of a test that is based on a citrullinated antigen is the possibility that antibodies are not directed exclusively to the citrulline-containing epitope but also to other possibly overlapping epitopes present in the substrate antigen. This is particularly important when citrullinated versions of proteins like vimentin or fibrinogen are used. For example, it is known that antibodies to vimentin are present in several diseases different from RA $[12,13]$. This particular problem has been addressed for CCP2 by Vannini et al. [14]. They used ELISA plates containing the control CCP2 antigens (Arg instead of Cit in the same peptide context), produced and made available by Euro-Diagnostica, Arnhem, The Netherlands, in parallel to the normal CCP2 test. The results of these comparative studies showed that in RA and most non-RA rheumatic disease sera, anti-CCP reactivity indeed is citrullinedependent. However, in some patients, particularly autoimmune hepatitis patients, citrulline-independent reactivity with the antigen may occur. A positive CCP test in a rheumatic disease (almost always citrulline-specific) may thus suggest the future development of RA as has been suggested by several studies $[15,16]$. A positive test in a nonrheumatic disease (very often not citrulline-specific), for example, liver disease, should be interpreted with care [14].

\section{Anti-CCP2 Antibodies are Present Early in Disease and have Predictive Potential}

Because RA patients at first presentation often do not fulfill the criteria for the diagnosis/classification of RA, an early, highly predictive marker would greatly assist the clinician in reaching an early diagnosis. There are several studies indicating that the anti-CCP2 test provides this help (reviewed by [2]).

In the recently published EULAR recommendations for the management of early arthritis [16], a list of factors has been proposed that predict persistent and erosive disease. These factors include: number of swollen and tender joints, ESR or CRP, level of RF and anti-CCP antibodies, and radiographic erosions. Most of these factors were also mentioned as being important in the prediction of early erosive RA (Visser et al. [17]). Subsequent studies by the same group gave an indication of the relative importance of these factors. When expressed as odds ratios (OR), the data was as follows: arthritis of three or more joints, 5.0; 
radiographic erosions, 8.7 ; positive IgM-RF, 1.7; and positive anti-CCP2, 38.6 [18]. These and other data (see also [19]) clearly show that the presence of anti-CCP antibodies is an important and independent prognostic factor for radiographic progression in not only early arthritis but also in early rheumatoid arthritis [16, 20].

Recently, it has also been shown that IgM-CCP is present in early samples from both patients with undifferentiated arthritis (UA) and patients with RA as well as in follow-up samples from patients with RA. These data indicate the development of the anti-CCP isotype repertoire into full usage early in the course of arthritis and a continuous (re)activation of the RA-specific anti-CCP response during the further development of the disease [21].

It is, however, evident that besides the clinical and laboratory parameters mentioned above, some genetic factors are important as well. The effect of the HLA shared-epitope alleles on the development of ACPA has been firmly established. Citrullination is typically a process that occurs in apoptotic cells. Because such dying cells are generally removed from the environment via clearance by phagocytes, a process that is regulated by many genes, the immune system will normally not encounter citrullinated proteins. However, it has been shown that during inflammation, citrullinated proteins are detectable in the inflamed tissue, both in RA and non-RA patients [22]. This is probably caused by inefficient clearance of the massive numbers of dying cells, a process already described to occur in SLE [23]. This inefficient clearing could, in principal, also be the consequence of altered genes, i.e., the genetic background. The mere presence of citrullinated antigens in inflamed synovial tissue does not necessarily result in the occurrence of anti-CCP antibodies in serum or synovial fluid, neither in humans nor in mouse models of arthritis [24, 22]. Hill et al. [25] showed that the generation of anticitrulline antibody in mice actually is linked to the expression of the RA shared epitope (SE), and a similar link was also found in patients because the combination of SE, and anti-CCP has a very high predictive value for the future development of RA [26]. The specific structure of HLA molecules obviously plays an important role in the induction of autoimmunity to citrullinated proteins. These studies were extended by Huizinga et al. [27] who found that HLA-DRB1 alleles encoding the SE were only associated with anti-CCP positive RA and not with antiCCP negative RA. In contrast, anti-CCP negative RA appeared to be associated with HLA-DR3 [28]. Therefore, the presence of citrullinated antigens, together with the appropriate genetic background (the SE and probably other types of HLA), appears to be the minimum requirement for an immune response to citrullinated polypeptides to be generated [29]. Next to that, other sensitizing genetic settings resulting from polymorphisms (e.g., PTPN22
[30]) might, given their association, aid in triggering of ACPA.

\section{Conclusions and Future Perspectives}

The present literature describes and confirms that the antiCCP2 test is a very useful marker for the early and accurate diagnosis of RA. Anti-CCP antibody is very specific for RA and has a sensitivity comparable to that of RF. These antibodies can be detected very early in disease and may be used as an indicator for the progression and prognosis of RA. Initially, the test was available principally as a manual ELISA method through Euro-Diagnostica and Axis-Shield and their partners. More recently, fully automated anti-CCP assays have also been made available from Phadia (UniCap Elia CCP) and Abbott Diagnostics (AxSYM anti-CCP). A very novel format is the CCPoint, a Point-of-Care test for the detection of these antibodies in whole blood in $10 \mathrm{~min}$ [31]. A small drop of whole blood is applied onto the sample well followed by the addition of four drops of running buffer. After $10 \mathrm{~min}$, the result is read by visual inspection of the detection zone for staining of the antigen line. As no special equipment is required to perform the assay, this test will bring the detection of anti-CCP antibodies into the office of the family doctor, facilitating a very fast referral to the rheumatologist when the test gives a positive answer. Such new applications will undoubtedly further enhance the utility of the anti-CCP autoantibody system in clinical practice.

\section{References}

1. Schellekens GA, Visser H, de Jong BA et al (2000) Arthritis Rheum 43:155-163

2. van Venrooij WJ, Zendman AJ, Pruijn GJ (2006) Autoimmun Rev 6:37-41

3. Cantaert T, De Rycke L, Bongartz T et al (2006) Arthritis Rheum 54:3381-3389

4. Agrawal S, Misra R, Aggarwal A (2007) Clin Rheumatol 26:201204

5. del Val del Amo N, Ibanez BR, Fito MC et al (2006) Clin Exp Rheumatol 24:281-286

6. Zendman AJ, van Venrooij WJ, Pruijn GJ (2006) Rheumatology (Oxford) 45:20-25

7. Dejaco C, Klotz W, Larcher H et al (2006) Arthritis Res Ther 8: R119

8. Anzilotti C, Merlini G, Pratesi F et al (2006) J Rheumatol 33:647651

9. Nielen MM, van der Horst AR, van Schaardenburg D et al (2005) Ann Rheum Dis 64:1199-1204

10. van der Cruyssen B, Cantaert T, Nogueira L et al (2006) Arthritis Res Ther 8:R122

11. Coenen D, Verschueren P, Westhovens R, Bossuyt X (2007) Clin Chem 55:498-504 
12. Yang Y, Fujita J, Bandoh S et al (2002) Clin Exp Immunol 128:169-174

13. FranchA,CastelloteC,VilaJLetal(1994)JRheumatol21:489-497

14. Vannini A, Cheung K, Fusconi M et al (2007) Ann Rheum Dis 66:511-516

15. Rantapää-Dahlqvist S, de Jong BA, Berglin E et al (2003) Arthritis Rheum 48:2741-2749

16. Combe B, Landewe R, Lukas C et al (2007) Ann Rheum Dis $66: 34-45$

17. Visser H, le Cessie S, Vos K et al (2002) Arthritis Rheum 46:357-365

18. van Gaalen FA, Linn-Rasker SP, van Venrooij WJ et al (2004) Arthritis Rheum 50:709-715

19. Matsui T, Shimada K, Ozawa N et al (2006) J Rheumatol 33:2390-2397

20. van der Helm-van Mil AH, Huizinga TW (2006) Future Rheumatol 1:79-89

21. Verpoort KN, Jol-van der Zijde CM, Papendrecht-van der Voort EA et al (2006) Arthritis Rheum 54:3799-3808

22. Vossenaar ER, Smeets TJ, Kraan MC et al (2004) Arthritis Rheum 50:3485-3494
23. Ren Y, Tang J, Mok MY et al (2003) Arthritis Rheum 48:28882897

24. Vossenaar ER, Nijenhuis S, Helsen MM et al (2003) Arthritis Rheum 48:2489-2500

25. Hill JA, Southwood S, Sette A et al (2003) J Immunol 171:538541

26. Berglin E, Padyukov L, Sundin E et al (2004) Arthritis Res Ther 6:R303-R308

27. Huizinga TW, Amos CI, van der Helm-van Mil AH et al (2005) Arthritis Rheum 52:3433-3438

28. Verpoort KN, van Gaalen FA, van der Helm-van Mil AH et al (2005) Arthritis Rheum 52:3058-3062

29. Irigoyen P, Lee AT, Wener MH et al (2005) Arthritis Rheum 52:3813-3818

30. Johansson M, Arlestig L, Hallmans G, Rantapää-Dahlqvist S (2005) Arthritis Res Ther 8:R19

31. Verheijen R, van Boekel MA, Peters M, Salden MH (2006) Abstracts of the 5th International Congress on Autoimmunity, Sorrento November 2006, p. 222, published in a special issue of Autoimmunity Reviews 